Research Article

\title{
A Cloud Model-Based Risk Assessment Methodology for Tunneling-Induced Damage to Existing Tunnel
}

\author{
Tian Xu $\mathbb{D}^{1,2}$ Zhanping Song $\mathbb{D}^{1,2}$ Desai Guo $\mathbb{D}^{1,2}$ and Yuncai Song ${ }^{3}$ \\ ${ }^{1}$ School of Civil Engineering, Xi'an University of Architecture and Technology, Xi'an 710055, China \\ ${ }^{2}$ Shaanxi Key Laboratory of Geotechnical and Underground Space Engineering, Xi'an 710055, China \\ ${ }^{3}$ China Railway Construction Bridge Engineering Bureau Group Co., Ltd., Tianjin 300300, China
}

Correspondence should be addressed to Zhanping Song; songzhpyt@xauat.edu.cn

Received 2 October 2020; Revised 11 November 2020; Accepted 25 November 2020; Published 7 December 2020

Academic Editor: Yi Zhang

Copyright ( 92020 Tian Xu et al. This is an open access article distributed under the Creative Commons Attribution License, which permits unrestricted use, distribution, and reproduction in any medium, provided the original work is properly cited.

\begin{abstract}
This study presents a cloud model-based approach for risk assessment of existing tunnels in tunneling construction environments where the cloud model provides a basis for uncertainty transformation between its qualitative concepts and quantitative expressions. An evaluation index system is established for risk assessment of existing tunnels based on the tunnel-induced failure mechanism analysis. The assessment result is obtained through the correlation with the cloud model of each risk level. Risk assessment for existing Guangzhou-Shenzhen-Hong Kong Railway Tunnel in the tunneling environment of Shenzhen Metro Line 6 is shown in a case study. Comparisons between Fuzzy Analytic Hierarchy Process (FAHP) methods are further discussed according to results. The proposed evaluation method is verified to be more competitive as the fuzziness and randomness of uncertainties in the risk assessment system can be considered comprehensively. This method can serve as a decision-making tool for other similar project risk assessment methods to increase the likelihood of a successful project in an uncertain environment.
\end{abstract}

\section{Introduction}

In the past few decades, many infrastructures, such as metro system, were constructed in congested megacities in China. The construction of some metro tunnels needs to be carried out above or near existing tunnels due to the limited underground space. The disturbance from the tunneling construction may affect the safety of the existing tunnel in such surrounding strata[1,2]. Such safety issues will be more prominent with the rapid increase of speed and scale of metro tunnel construction in China. It is urgent and necessary to conduct risk assessments on existing tunnels in order to ensure their safety in tunneling construction environments.

Many factors have contributed to the damage of existing tunnels in tunneling construction environments, e.g., geological conditions, proximity, and tunnel structure. An effective risk assessment approach should have the ability to consider all relevant factors and calculate the degree of influence of each factor on the assessment result
[3]. The risk assessment of underground engineering is systematic, and a single evaluation approach is not always sufficient to obtain better results in such a complex evaluation work. Therefore, a comprehensive evaluation method is required for risk assessment of such systems engineering processes. Current comprehensive evaluation approaches can be grouped into the following three categories [4-6]: (1) approaches based on fuzzy mathematics theory, e.g., fuzzy analytic hierarchy process; (2) approaches based on probability and statistics theory, e.g., Bayesian networks; (3) approaches based on artificial intelligence, e.g., neural networks. The current construction equipment and technology have become more intelligent and digital than the past ones; however, construction data are difficult to collect in engineering practice as the contractors are unwilling to publish data to the public. Some limitations exist in the application of approaches (2) and (3) due to a lack of sufficient data. The uncertainties existing in experiential data can be considered in terms of intervals or fuzzy numbers in risk assessment [7]. At present, the 
fuzzy mathematics-based assessment method is commonly used in the risk assessment of underground engineering. Lan and Zhang [8] carried out a risk assessment of the construction period of a deep foundation pit based on fuzzy theory. They used expert evaluation to determine the accident probability level and loss level estimates. The appropriate membership function curve was selected according to the degree of confidence and the project risk level was obtained by comprehensive evaluation. Zhou and Cao [9] developed an optimal supporting model of deep foundation pit in soft soil area based on the theory of fuzzy mathematics. Chen and Zhan [10] summarized the accident cases of surrounding buildings caused by tunnel construction. The fuzzy interval algorithm was used to obtain the occurrence probability of the evaluation target and the fuzzy importance of each risk factor. The improved model was verified by an engineering example. However, in conventional fuzzy mathematics-based methods, the sectional fuzzy function should be determined individually concerning each evaluation factor [11], which affects the accuracy and reliability of the calculation results due to human error. In addition, correspondence relations between the evaluation index and the attribute measurement are one-to-one. In reality, there is uncertainty in the attribute measurement corresponding to the evaluation index, which leads to the randomness of the risk assessment.

The cloud model is a quantitative and qualitative uncertainty transformation model first proposed by $\mathrm{Li}$ et al. [12]. It has the capability of expressing fuzziness and randomness existing in human knowledge representation. The cloud model expresses the relationship between the assessment index value and the risk level by expectation $\left(E_{x}\right)$, entropy $\left(E_{n}\right)$, and hyperentropy $\left(H_{e}\right)$. It reflects the uncertainty between the two in the form of the point membership function, and the mapping relationship between the evaluation index and attribute measure is one-to-many.

In view of the advantages of the cloud model theory, we introduce it into the risk assessment of an existing tunnel in tunneling construction environments. The uncertainty relationship between evaluation index and risk level is established by cloud model theory. Finally, the proposed approach is applied to the risk assessment of the Guangzhou-Shenzhen-Hong Kong Railway Tunnel adjacent to Shenzhen Metro Line 6 tunnel construction in a case study. The comparisons between the proposed approach and other traditional methods are further discussed accordingly.

\section{Methods}

2.1. Cloud Model. Let $U$ be a quantitative domain represented by a precise number that is one-dimensional or multidimensional. $T$ is defined as a qualitative concept in $U$. The membership degree of $x$ belonging to $T$ is a random number with stable tendency $\mu$. The distribution of $x$ in domain $U$ is defined as a cloud model. $(x, \mu)$ can be regarded as a cloud drop. Qualitative concept $T$ is the mapping from domain $U$ to the interval $(0,1)$ in the cloud model, as shown in

$$
\mu_{T}(x): U \longrightarrow[0,1], \forall x \in U, x \longrightarrow \mu_{T}(x) .
$$

The comprehensive feature of cloud model theory is represented by three numerical characteristics $\left(E_{x} E_{n} H_{e}\right) . E_{x}$ is the expectation, which can best reflect the qualitative concept of a quantitative value; $E_{n}$ is entropy, which represents the uncertainty of qualitative concept judgment. The greater the value of $E_{n}$, the greater the fuzziness and randomness of qualitative concept judgment. $H_{e}$ is hyperentropy, which represents the uncertainty of entropy. The higher the hyperentropy is, the more discrete the cloud drops in the cloud model graph will be, which means the greater the randomness of the membership degree. Using $\left(E_{x} E_{n} H_{e}\right)$ to express a qualitative concept, we can better conform to the essence of evaluation in an actual project

Different types of cloud models can be formed by choosing different probability distribution functions. A normal cloud model is built on a normal distribution and Gaussian membership function. The cloud model that conforms to normal distribution is verified with better applicability and distinct mathematical properties when it is applied to natural social sciences [13] and is therefore adopted in this research. The normal cloud model is described as follows: if quantitative value $x$ satisfies $x \sim N\left(E_{x}\right.$, $\left.E_{n n}{ }^{2}\right), E_{n n} \sim N\left(E_{n}, H_{e}^{2}\right)$ and the membership degree of $x$ to qualitative concept $T$ satisfies equation (2), then the distribution of $x$ in quantitative domain $U$ is regarded as a normal cloud:

$$
\mu_{T}(x)=\exp \left(\frac{-\left(x-E_{x}\right)^{2}}{2\left(E_{\mathrm{nn}}\right)^{2}}\right)
$$

In order to make it easy for the reader to understand the cloud model, Figures 1(a), 1(b), 1(c), and 1(d) show the cloud model image with different $E_{x}, E_{n}, H_{e}$ and cloud drops numbers, respectively.

The cloud drops are generated by a cloud drop generator, which establishes the mapping relationship between the qualitative concept and quantitative characteristic. The cloud drop generator can be basically divided into the forward drop generator and the backward drop generator, which comprise the two main algorithms of the cloud model. The forward cloud generator is used to transform qualitative concept with three numerical characters $\left(E_{x} E_{n} H_{e}\right)$ into multiple cloud drops, whereas the backward cloud transforms a group of cloud drops into the three characters [14]. The forward cloud generator is used to generate cloud drops of the given cloud numerical characters in this study.

\subsection{Developing Risk Assessment Model}

2.2.1. Existing Tunnel Risk Evaluation Index. A reasonable risk evaluation index system is the foundation of an effective risk assessment model. The risk evaluation of an existing tunnel adjacent to tunneling construction is a complex problem involving many influencing factors. However, the evaluation index is not as many as possible. The evaluation process will become complicated if it involved too many 


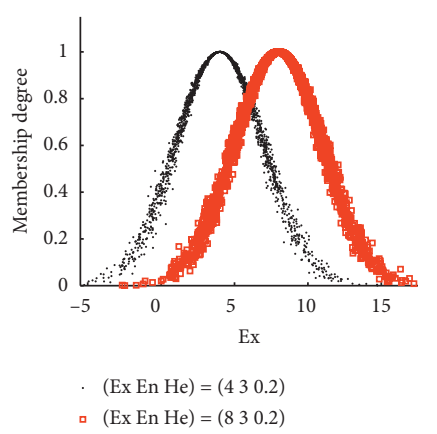

(a)

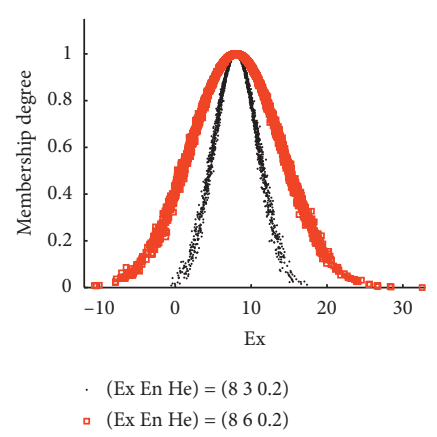

(b)

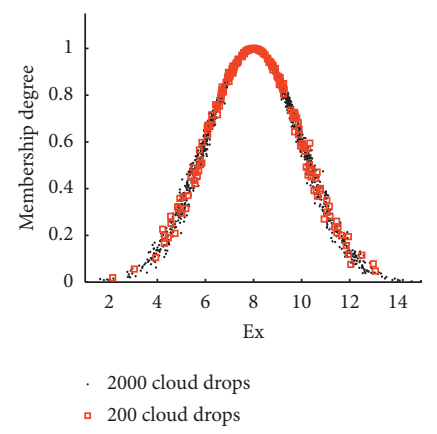

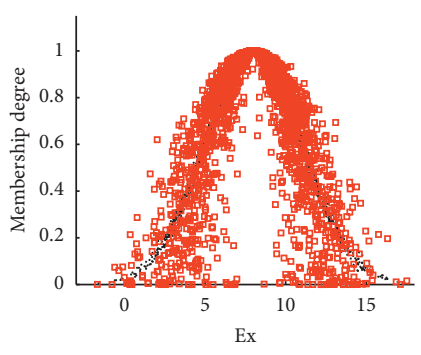

$($ Ex En He $)=\left(\begin{array}{lll}8 & 3 & 0.1\end{array}\right)$

口 $($ Ex En He $)=\left(\begin{array}{lll}8 & 3 & 1\end{array}\right)$

(c)

(d)

Figure 1: Cloud models with different numerical characteristics.

evaluation indicators, as considering many nonmain factors will affect the accuracy of the evaluation results. At present, there are no universal guidelines for the selection of the risk assessment indicators in tunneling construction. The risk evaluation indicators of an existing tunnel adjacent to the tunneling construction were analyzed and selected, and the evaluation index system based on the four principles of the risk evaluation indicators, that is, selection, systematization, representativeness, feasibility, and easy quantification, was established in this study $[15,16]$.

In real projects, the risk evaluation index of an existing tunnel adjacent to the tunneling excavation involved in tunnel-soil-tunnel interaction should be considered Tunnel excavation destroys the original equilibrium state of the surrounding rock and causes rock mass deformation. If the existing tunnel is within the influence range of the surrounding rock, the deformation will act on the structure of the existing tunnel. When the tunnel structure is subjected to external forces, it will produce uplift, deformation, and other failure forms, which will affect the safety of the existing tunnel. Based on the above analysis along with a large amount of literature research and engineering practice [17-20], the existing tunnel structural characteristics and the new tunnel construction characteristics are the main factors affecting the existing tunnel safety. According to these two main factors, the risk evaluation indicators are determined as follows.

(1) Existing Tunnel Characteristics. The safety risk of the existing tunnel, on the one hand, is related to the external environment, e.g., the distance between the existing tunnel and new tunnel $\left(C_{1}\right)$ and the crossing angle between the existing tunnel and new tunnel $\left(C_{2}\right)$ [21]. These two evaluation indicators have an obvious contribution to the vertical deformation of the existing tunnel. On the other hand, existing tunnel safety risk is related to the existing tunnel itself, e.g., water seepage degree of existing tunnel structure $\left(C_{3}\right)$ and cumulative width of cracks of the existing tunnel structure $\left(C_{4}\right) . C_{3}$ has effect on the stability of existing tunnel structure and traffic safety, and $\mathrm{C}_{4}$ has an effect on the overall stiffness of the existing tunnel [22].

(2) Tunneling Construction Characteristics. The parameters related to tunneling construction are the factors that have an important influence on the adjacent existing tunnel safety; e.g., the surrounding rock grade of the new tunnel $\left(C_{5}\right)$ reflects the nature of rock mass within the influence range of tunneling excavation comprehensively, which greatly damages the stability of the adjacent existing tunnel. In the same species of surrounding rock, the greater the span of the new tunnel $\left(C_{6}\right)$, the worse the stability of surrounding rock and the greater the damage on the existing tunnel. Buried depth of the new tunnel $\left(C_{7}\right)$ also has a great influence on the surrounding rock stability. The smaller $C_{7}$ is, the more difficult it is to stabilize the tunnel. Excavation method of the new tunnel $\left(C_{8}\right)$ has an impact on the surrounding environment. For the same tunnel section, different excavation methods have different stress distribution and damage to surrounding rock and therefore have different impacts on the adjacent existing tunnel. Tunneling construction causes compression deformation of the surrounding rock due to 
stress redistribution, which leads to deformation of adjacent existing tunnels. Since surrounding rock deformation is related to hydrogeological conditions, hydrogeological conditions should be used as a risk evaluation index for the existing tunnel's safety $\left(C_{9}\right)$. Figure 2 shows the risk evaluation index system of the existing tunnel in a tunneling construction environment according to the above analysis.

2.2.2. Risk Level Gradation. Among the above eight assessment indicators in risk assessment of existing tunnel, some are objective, such as $C_{1}, \ldots, C_{7}$, whereas others, such as $C_{3}, \ldots, C_{9}$, are subjective. Both the objective and subjective factors are gathered together to quantify the level of the risk for the existing tunnel due to tunneling excavation. The objective indicators are measured by the observed values in projects and the subjective indicators are measured by evaluated values from domain experts using a 100-mark system [23]. As each indicator in the risk assessment of the existing tunnel contributes to the final risk level, it is necessary to evaluate the risk status of those assessment indicators. In this study, the risk status of each assessment indicator is divided into five different levels (I, II, III, IV, and V). The corresponding evaluation languages are as follows: extreme risk, high risk, average risk, low risk, and no risk.

However, the boundary of each risk interval is vague in determination due to complexities in tunneling construction environments. With the increase of tunnel construction in China, large amounts of decentralized knowledge have been accumulated from practice, such as monitoring records, standard specifications, and research reports. Moreover, many scholars have established simulation models for security analysis, which provide effective references for discovering the relationship between various risks and risk factors [24, 25]. These resources provide prior knowledge for the understanding of evolutionary patterns of risk indicators. This study proposes the risk classification results of the risk assessment indicators of the existing tunnel affected by the tunneling excavation, as shown in Table 1, based on this prior knowledge.

2.2.3. Membership Degree Calculation Based on the Cloud Model. Membership degree is used to measure the relative degree between the evaluation index and cloud model of each risk level. Membership degree calculation plays a critical role in the risk assessment when the cloud model is adopted. Assume that $x_{i}$ represents the actual value of $i^{\text {th }}$ evaluation index. $x_{i}$ does not need to be normalized before being entered into the cloud model, which can avoid the diversity information loss of evaluation index after normalization. This study used the MATLAB Compiler to achieve exiting tunnel risk assessment under tunneling environment based on the cloud model, adopting the specific steps outlined in the following.
(1) Cloud Image. According to the risk grade threshold range of the indicator in Table 1 , the expectation $\left(E_{x}\right)$, entropy $\left(E_{n}\right)$, and hyperentropy $\left(H_{e}\right)$ of the indicator with different grades are obtained. The calculation basis of $\left(E_{x}\right),\left(E_{n}\right)$, and $\left(H_{e}\right)$ is described in detail in [14]. The calculation formula is expressed as

$$
\begin{aligned}
& E_{x}=\frac{\left(C_{\min }+C_{\max }\right)}{2}, \\
& E_{n}=\frac{\left(C_{\max }-C_{\min }\right)}{6}, \\
& H_{e}=k E_{n},
\end{aligned}
$$

where $C_{\min }$ and $C_{\max }$ are the threshold minimum limit and maximum limit of risk level $j$, respectively. In this study, the form $H_{e}=k E_{n} \quad(0<k<1 / 3)$ is adopted and(1)Cloud Image. According to the risk grade threshold range of the indicator in Table 1 , the expectation $\left(E_{x}\right)$, entropy $\left(E_{n}\right)$, and hyperentropy $\left(H_{e}\right)$ of the indicator with different grades are obtained. The calculation basis of $\left(E_{x}\right),\left(E_{n}\right)$, and $\left(H_{e}\right)$ is described in detail in [14]. The calculation formula is expressed as the value of $k=0.1$ is chosen to maintain the stability of the evaluation [26-29]. According to equation (3), all the evaluation indicators in Table 1 can be converted into digital features for cloud model calculation, and the calculation results are shown in Table 2.

The forward cloud generator was used to generate the evaluation index cloud image. The cloud models of risk assessment indicators are shown in Figure 3. For the five clouds of the evaluation grade, each grade has a set of digital characteristics $\left(E_{x} E_{n} H_{e}\right)$.

(2) Membership Degree Calculation. The actual value of the evaluation index as $x_{i}$ is viewed as a cloud drop. Its membership degree as $r_{i j}$ can then be calculated using equation (2). As the distribution of cloud drops is taken in the forward cloud generation with a certain extent random, the results of a cloud model run are different. The cloud model of the existing tunnel is run 1000 times to calculate the average values of the membership degree to obtain a stable and reliable membership degree [30], which is shown in

$$
\mu=\frac{1}{1000} \sum_{i=1}^{1000} \mu_{T}(x) .
$$

(3) The membership degree matrix of the existing tunnel risk evaluation $r$, represented by $R$, can be then obtained using equation (5). The membership degree calculation process was programmed by MATLAB 2019: 


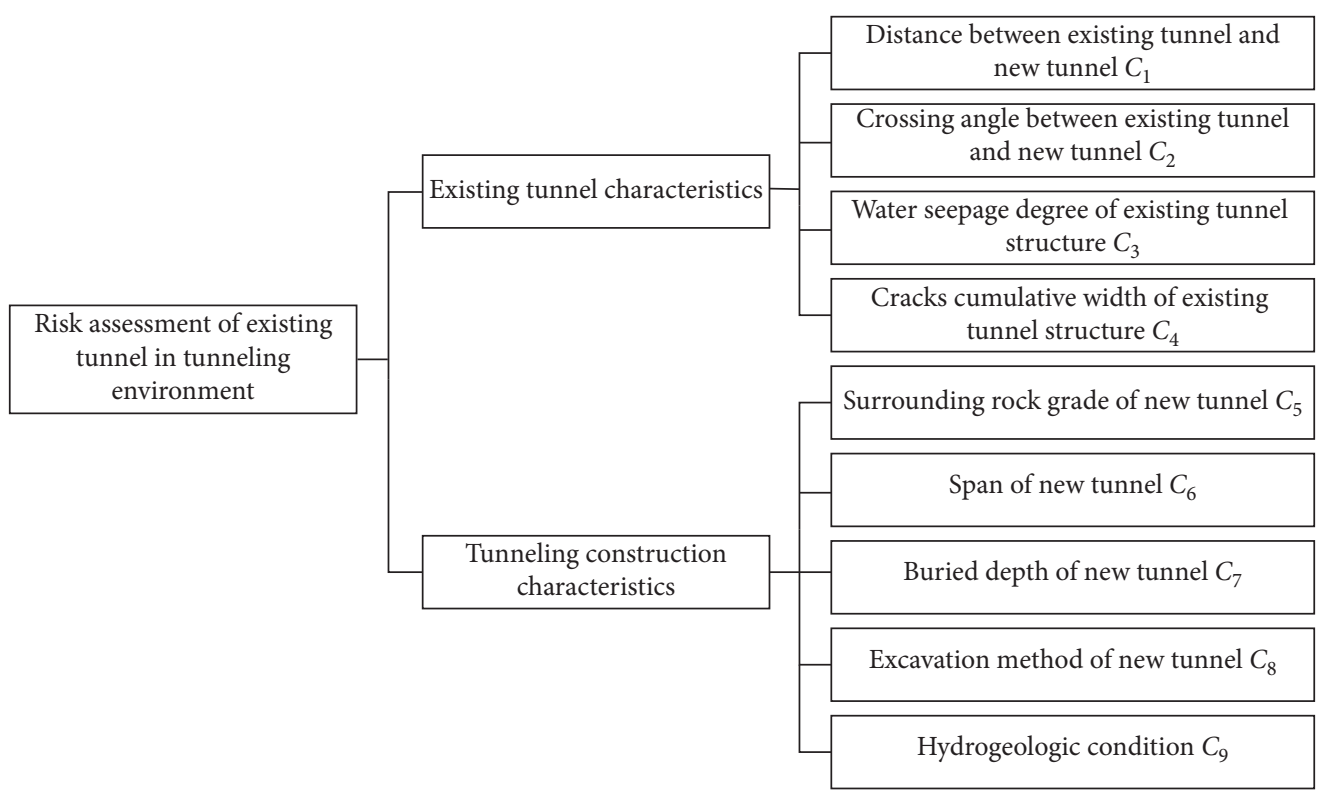

FIGURE 2: The risk evaluation index system of the existing tunnel in a tunneling construction environment.

TABLE 1: Classification of risk level for assessment index.

\begin{tabular}{|c|c|c|c|c|c|}
\hline \multirow{2}{*}{$\begin{array}{l}\text { Evaluation } \\
\text { index }\end{array}$} & \multicolumn{5}{|c|}{ Risk evaluation level } \\
\hline & $\mathrm{I}$ & II & III & IV & $\mathrm{V}$ \\
\hline $\mathrm{C}_{1}$ & $>30$ & {$[20,35]$} & {$[10,22]$} & {$[3,12]$} & $<4$ \\
\hline $\mathrm{C}_{2}$ & {$[70,90]$} & {$[50,75]$} & {$[30,55]$} & {$[20,35]$} & {$[0,25]$} \\
\hline $\mathrm{C}_{3}$ & {$[80,100]$} & {$[60,80]$} & {$[40,60]$} & {$[20,40]$} & {$[0,20]$} \\
\hline $\mathrm{C}_{4}$ & $<0.6$ & {$[0.5,1.1]$} & {$[0.9,1.3]$} & {$[1.2,1.6]$} & $>1.4$ \\
\hline $\mathrm{C}_{5}$ & I $[80,100]$ & II $[60,80]$ & III $[40,60]$ & IV $[20,40]$ & $\mathrm{V}[0,20]$ \\
\hline $\mathrm{C}_{6}$ & $<5$ & {$[4,10]$} & {$[8,15]$} & {$[14,20]$} & $>18$ \\
\hline $\mathrm{C}_{7}$ & $>60$ & {$[20,30]$} & {$[15,20]$} & {$[10,15]$} & $<10$ \\
\hline $\mathrm{C}_{8}$ & TBM $[80,100]$ & $\begin{array}{l}\text { Double side drift }[60, \\
80]\end{array}$ & CD or CRD $[40,60]$ & Bench cut $[20,40]$ & Full section $[0,20]$ \\
\hline $\mathrm{C}_{9}$ & $\begin{array}{l}\text { The hydrogeological } \\
\text { condition is good and } \\
\text { there is no bad geological } \\
\text { condition. The } \\
\text { groundwater level is } \\
\text { below the newly built } \\
\text { tunnel }[80,100]\end{array}$ & $\begin{array}{l}\text { The hydrogeological } \\
\text { condition is good and } \\
\text { there is no bad } \\
\text { geological condition. } \\
\text { The groundwater level } \\
\text { is low }[60,80]\end{array}$ & $\begin{array}{l}\text { The hydrogeological } \\
\text { condition is normal and } \\
\text { there is no obvious bad } \\
\text { geological condition. } \\
\text { The groundwater level is } \\
\text { low }[40,60]\end{array}$ & $\begin{array}{l}\text { The geological } \\
\text { condition is poor } \\
\text { (expansive soil, } \\
\text { frozen soil, } \\
\text { collapsible loess, soft } \\
\text { soil, etc.). The } \\
\text { groundwater level is } \\
\text { high }[20,40]\end{array}$ & $\begin{array}{l}\text { The geological } \\
\text { condition is poor } \\
\text { (expansive soil, frozen } \\
\text { soil, collapsible loess, } \\
\text { soft soil, etc.). The } \\
\text { groundwater is rich } \\
\text { and distribution is } \\
\text { shallow }[0,20]\end{array}$ \\
\hline
\end{tabular}

TABLE 2: Numerical characteristics of risk level for assessment index.

\begin{tabular}{lccccc}
\hline Evaluation index & I & II & III & IV & V \\
& $\left(E_{x} E_{n} H_{e}\right)$ & $\left(E_{x} E_{n} H_{e)}\right.$ & $\left(E_{x} E_{n} H_{e}\right)$ & $\left(E_{x} E_{n} H_{e}\right)$ & $\left(E_{x} E_{n} H_{e}\right)$ \\
\hline$C_{1}$ & $(40,3.33,0.333)$ & $(27.5,2.5,0.25)$ & $(16,2,0.2)$ & $(7.5,1.5,0.15)$ & $(2,0.67,0.067)$ \\
$C_{2}$ & $(80,3.33,0.333)$ & $(62.5,4.167,0.4167)$ & $(42.5,4.167,0.4167)$ & $(27.5,4.167,0.4167)$ & $(12.5,4.167,0.4167)$ \\
$C_{3}$ & $(90,3.33,0.333)$ & $(70,3.33,0.333)$ & $(50,3.33,0.333)$ & $(30,3.33,0.333)$ & $(10,3.33,0.333)$ \\
$C_{4}$ & $(0.3,0.1,0.01)$ & $(0.8,0.1,0.01)$ & $(1.1,0.067,0.0067)$ & $(1.4,0.067,0.0067)$ & $(2.2,0.27,0.027)$ \\
$C_{5}$ & $(90,3.33,0.333)$ & $(70,3.33,0.333)$ & $(50,3.33,0.333)$ & $(30,3.33,0.333)$ & $(10,3.33,0.333)$ \\
$C_{6}$ & $(2.5,0.833,0.0833)$ & $(7,1,0.1)$ & $(11.5,1.17,0.117)$ & $(17,1.67,0.167)$ & $(24,2,0.2)$ \\
$C_{7}$ & $(42.5,5.83,0.583)$ & $(24,2,0.2)$ & $(16.5,1.17,0.117)$ & $(11.5,1.17,0.117)$ & $(5,1.67,0.167)$ \\
$C_{8}$ & $(90,3.33,0.333)$ & $(70,3.33,0.333)$ & $(50,3.33,0.333)$ & $(30,3.33,0.333)$ & $(10,3.33,0.333)$ \\
$C_{9}$ & $(90,3.33,0.333)$ & $(70,3.33,0.333)$ & $(50,3.33,0.333)$ & $(30,3.33,0.333)$ & $(10,3.33,0.333)$ \\
\hline
\end{tabular}



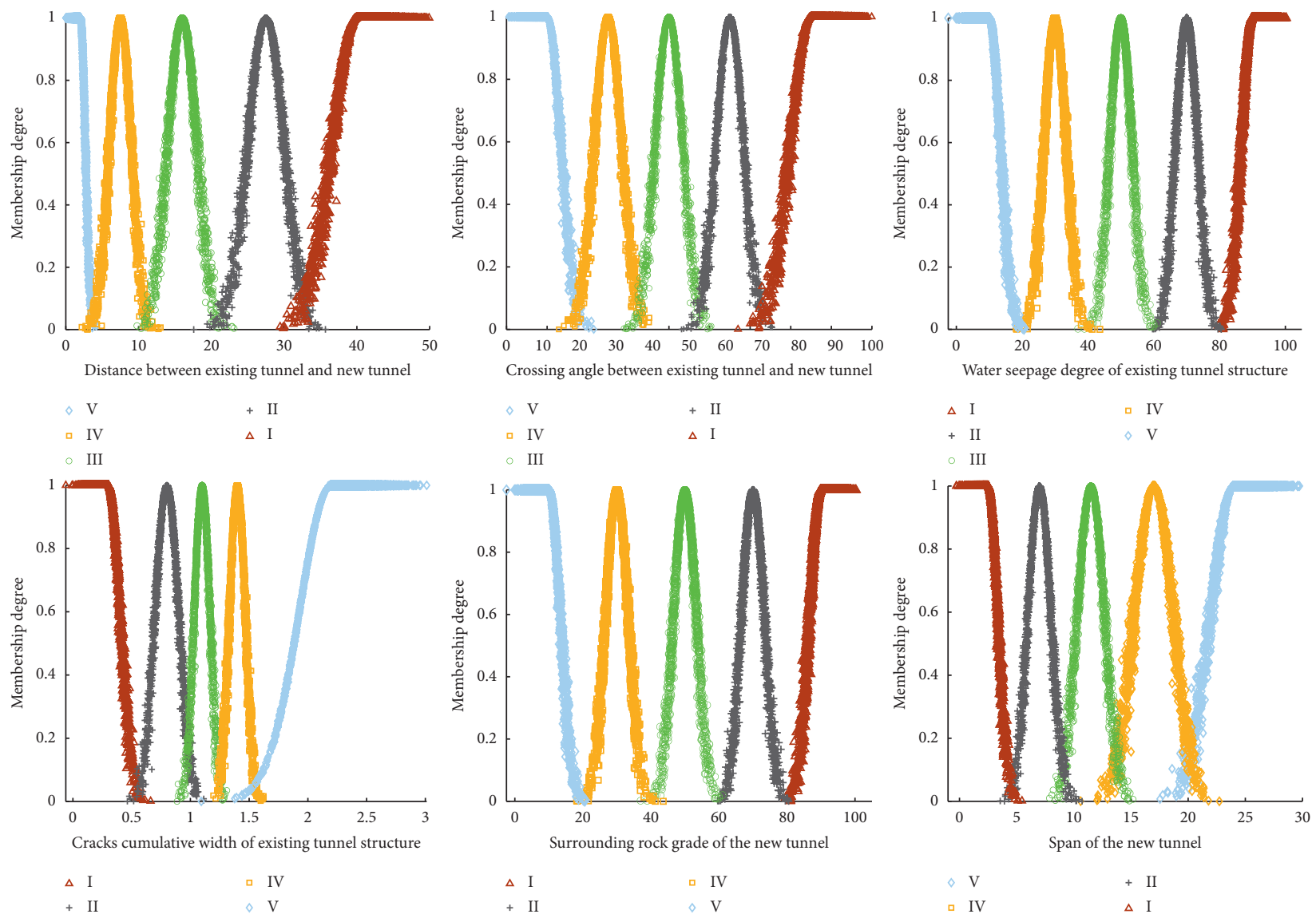

+ II
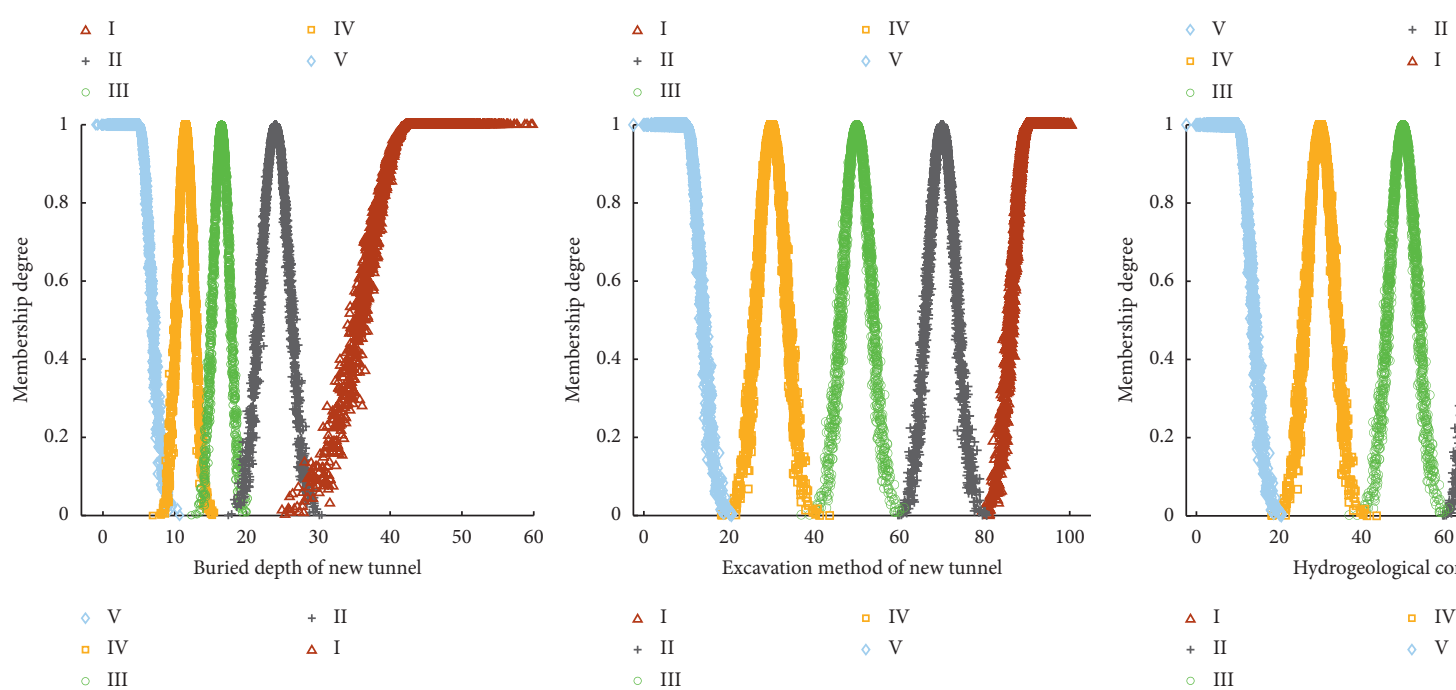

ㅁ IV

$\Delta \mathrm{I}$

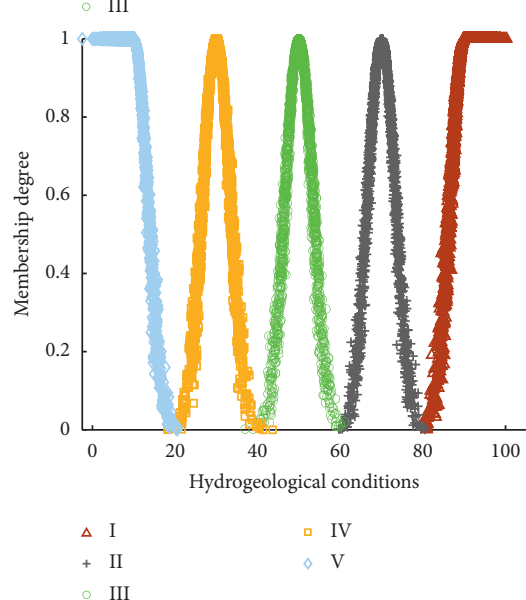

Figure 3: The cloud models of assessment indicators of the risk level for the existing tunnel.

$$
R=\left[\begin{array}{cccc}
r_{11} & r_{12} & \ldots & r_{1 j} \\
r_{12} & 1 & \ldots & a_{2 n} \\
\ldots & \ldots & \ldots & \ldots \\
r_{i 1} & r_{i 2} & \ldots & r_{i j}
\end{array}\right],
$$

where $\mathbf{r}_{\mathbf{i j}}$ is the membership degree of $i^{\text {th }}$ evaluation index to risk level $j$.

It should be noted that, in fact, the distribution of the clouds with risk grade at the two ends of the existing tunnel risk assessment levels $I$ and $V$ away from the middle cloud should be a uniform distribution with a certainty of 1 . The corresponding membership degree calculation formula is different and obtained from [31].

2.2.4. Weight Determination. The analytic hierarchy process (AHP), developed by Saaty, is a structured technique for organizing and analyzing complex decisions, based on mathematics and psychology [32]. It represents an accurate approach for quantifying the weights of decision criteria. The main idea is to break down the evaluation system into a 
hierarchy structure and compare each element according to a principle. In detail, experts are invited to acquire the comparison matrix elements by the pairwise comparison method. In pair comparison of evaluation index, if the priority of element $i$ compared to element $j$ is equal to $a_{i j}$, then the priority of element $j$ compared to element $i$ is equal to $1 / a_{i j}$. The priority of the element compared to it is equal to one. The comparison criterion used in this study is the most commonly used nine-scale method [33], which is shown in Table 3. If the evaluation index involves all factors of $m$, the paired comparison matrix is shown inwhere $n$ is the number of evaluation indexes and $a_{i j}$ is the importance degree of $i^{\text {th }}$ evaluation index relative to $j^{\text {th }}$ risk level in the judgment matrix.

$$
A=\left(a_{i j}\right)_{n \times n}\left[\begin{array}{cccc}
1 & a_{12} & \ldots & a_{1 n} \\
1 / a_{12} & 1 & \ldots & a_{2 n} \\
\ldots & \ldots & \ldots & \ldots \\
1 / a_{1 n} & 1 / a_{2 n} & \ldots & 1
\end{array}\right]
$$

As various decision-makers always make inconsistent judgments, the matrix should be tested for consistency. If the matrix meets the requirement of consistency, the construction of the comparison matrix can be considered reasonable and feasible. The calculation formula of the consistency test is shown in equation (7).

$$
\mathrm{CR}=\frac{\left(\lambda_{\max }-n\right) /(n-1)}{\mathrm{RI}}
$$

where $\lambda_{\max }$ is the maximum eigenvalue of the matrix; RI is the average random consistency index and its value is determined according to Table 4 . The matrix meets the requirement of consistency when $C R<0.1$ [34]. The weight of the assessment index is calculated by equation (8). Finally, all the weights constitute weight vector $W$ in the assessment index system, as seen in

$$
\begin{gathered}
w_{i}=\frac{\sqrt[n]{\prod_{j=1}^{n} a_{i j}}}{\sum_{j=1}^{n}\left(\sqrt[n]{\left.\prod_{j=1}^{n} a_{i j}\right)}\right.}, \\
W=\left(w_{1}, w_{2}, \ldots, w_{i}\right),
\end{gathered}
$$

where $w_{i}$ represents the weight of $i^{\text {th }}$ evaluation index.

2.3. Safety Risk Assessment. Based on weight vector $W$ and membership degree matrix $R$, comprehensive evaluation vector $B$ can be calculated by

$$
B=W \cdot R \text {. }
$$

The flowchart of the existing tunnel risk level evaluation is shown in Figure 4.

\section{Case Study}

3.1. Background. Yangtaishan Tunnel section is a key project of Shenzhen Metro Line Six with $3293.5 \mathrm{~m}$ total length and $5.8 \mathrm{~m}$ span. This tunnel is undercrossing the
TABLE 3: AHP scale of nine points used in the paired comparatives.

\begin{tabular}{lc}
\hline Numerical assessment & Definitions \\
\hline 1 & Equally important \\
3 & Moderately more important \\
5 & Strongly more important \\
7 & Very strongly important \\
9 & Extremely more important \\
$2,4,6,8$ & Intermediate values of importance \\
$1 / 9,1 / 8, \ldots, 1 / 2$ & Reciprocal values (inverses) \\
\hline
\end{tabular}

TABle 4: Consistency random index (RI).

\begin{tabular}{cccccccccc}
\hline$n$ & 1 & 2 & 3 & 4 & 5 & 6 & 7 & 8 & 9 \\
\hline $\mathrm{RI}$ & 0 & 0 & 0.58 & 0.90 & 1.12 & 1.24 & 1.32 & 1.41 & 1.45 \\
\hline
\end{tabular}

Guangzhou-Shenzhen-Hong Kong Railway Tunnel and buried at a depth of $127.25 \mathrm{~m}$. The whole length of undercrossing is $100 \mathrm{~m}$, which is in the III-level surrounding rock, and TBM construction is adopted. The construction site contains loose rock pore water and bedrock fissure water, and local sections are subject to slight pressure. The average buried depth of groundwater is about $7.43 \mathrm{~m}$ and the groundwater elevation is generally 61.49-161.64 $\mathrm{m}$. The undercrossing mileage of the railway left line tunnel is ZDK25+820-920 and the right line is YDK25+842-942. The structure type of GuangzhouShenzhen-Hong Kong Railway Tunnel is a single cavern and double line with $14.4 \mathrm{~m}$ section wide and $12.18 \mathrm{~m}$ high. Guangzhou-Shenzhen-Hong Kong Railway Tunnel is located in slightly weathered granite. The initial support of the Guangzhou-Shenzhen-Hong Kong Railway Tunnel uses $15 \mathrm{~cm}$ thick C25 shotcrete, and the second lining is $40 \mathrm{~cm}$ thick $\mathrm{C} 30$ concrete. The soil between the two tunnels is slightly weathered granite, the tunnel distance is $30.07 \mathrm{~m}$, and the intersection angle is $25^{\circ}$. The positional relationship between the two tunnels is shown in Figures 5 and 6.

When the Shenzhen Metro Line 6 Tunnel underpasses the Guangzhou-Shenzhen-Hong Kong Railway Tunnel, the displacement and stress field of the surrounding stratum are changed and the rock mass around is disturbed, inevitably causing deformation of the adjacent railway tunnel. Although the distance between the two tunnels is relatively long, the railway is built with advanced ballastless track technology, which is highly sensitive to deformation. Therefore, it is necessary to assess the risk level of the railway tunnel before the construction of the metro tunnel.

Integrated with the expert decision-making information simultaneously, the observed values of eight evaluation indicators for the adjacent Guangzhou-Shenzhen-Hong Kong Railway Tunnel are presented in Table 5.

3.2. Weight Vector and Membership Degree Matrix. In this study, seven relevant experts were invited to score eight evaluation indicators and evaluation index matrix $A$ was obtained: 


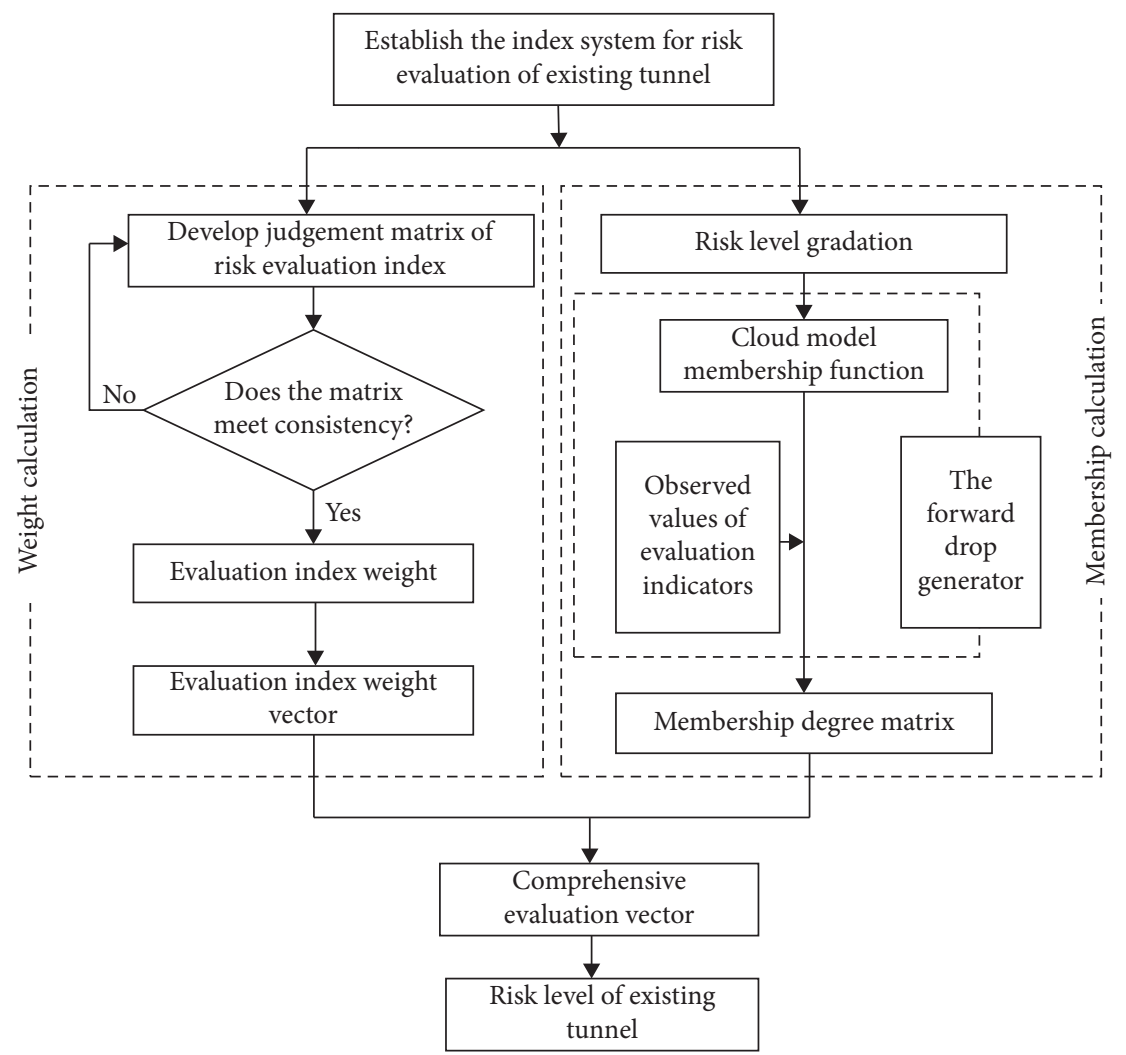

FIgURE 4: Flowchart of existing tunnel risk level evaluation.

$$
A=\left[\begin{array}{ccccccccc}
1 & 6 & 3 & 2 & 4 & 3 & 5 & 4 & 2 \\
\frac{1}{6} & 1 & \frac{1}{4} & \frac{1}{5} & \frac{1}{3} & \frac{1}{4} & \frac{1}{2} & \frac{1}{3} & 1 / 5 \\
\frac{1}{3} & 4 & 1 & \frac{1}{2} & 2 & 1 & 3 & 2 & 1 / 2 \\
\frac{1}{2} & 5 & 2 & 1 & 3 & 2 & 4 & 3 & 1 \\
\frac{1}{4} & 3 & \frac{1}{2} & \frac{1}{3} & 1 & \frac{1}{2} & 2 & 1 & 1 / 3 \\
\frac{1}{3} & 4 & 1 & \frac{1}{2} & 2 & 1 & 3 & 2 & 1 / 2 \\
\frac{1}{5} & 2 & \frac{1}{3} & \frac{1}{4} & \frac{1}{2} & \frac{1}{3} & 1 & \frac{1}{2} & 1 / 4 \\
\frac{1}{4} & 3 & \frac{1}{2} & \frac{1}{3} & 1 & \frac{1}{2} & 2 & 1 & 1 / 3 \\
1 / 2 & 5 & 2 & 1 & 3 & 2 & 4 & 3 & 1
\end{array}\right]
$$

Then, the weight of each evaluation index is calculated according to equation (8), and weight vector $W$ of the risk evaluation index of Guangzhou-Shenzhen-Hong Kong Railway Tunnel is obtained as follows:

$$
\begin{aligned}
W= & (0.2830,0.0472,0.0943,0.1415,0.0708,0.043,0.0566, \\
& 0.0708,01415) .
\end{aligned}
$$

The consistency evaluation result is $\mathrm{CR}=0.0130<0.1$, which indicates that the judgment matrix $A$ satisfies the consistency requirement.

According to the membership degree calculation method introduced in Section 2.2.3, membership degrees of the eight evaluation indicators are calculated by equation (2) and equation (4), which is shown in Table 6.

The result of the membership degree is expressed as matrix $R$ :

$$
R=\left[\begin{array}{ccccc}
0.1300 & 0.5900 & 0.000 & 0.000 & 0.000 \\
0.000 & 0.000 & 0.000 & 0.8340 & 0.0117 \\
0.000 & 0.000 & 1.0000 & 0.000 & 0.000 \\
0.000 & 0.1354 & 0.3284 & 0.000 & 0.000 \\
0.000 & 0.0113 & 0.0115 & 0.000 & 0.000 \\
0.000 & 0.4864 & 0.000 & 0.000 & 0.000 \\
1.0000 & 0.000 & 0.000 & 0.000 & 0.000 \\
0.0114 & 0.0112 & 0.000 & 0.000 & 0.000 \\
0.000 & 0.0113 & 0.0115 & 0.000 & 0.000
\end{array}\right] .
$$




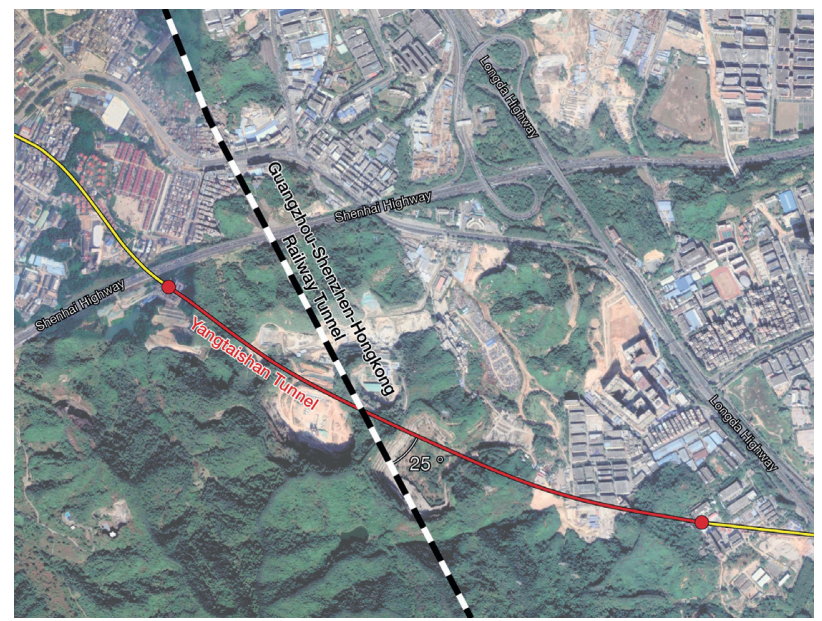

Figure 5: Plane position of the two tunnels.

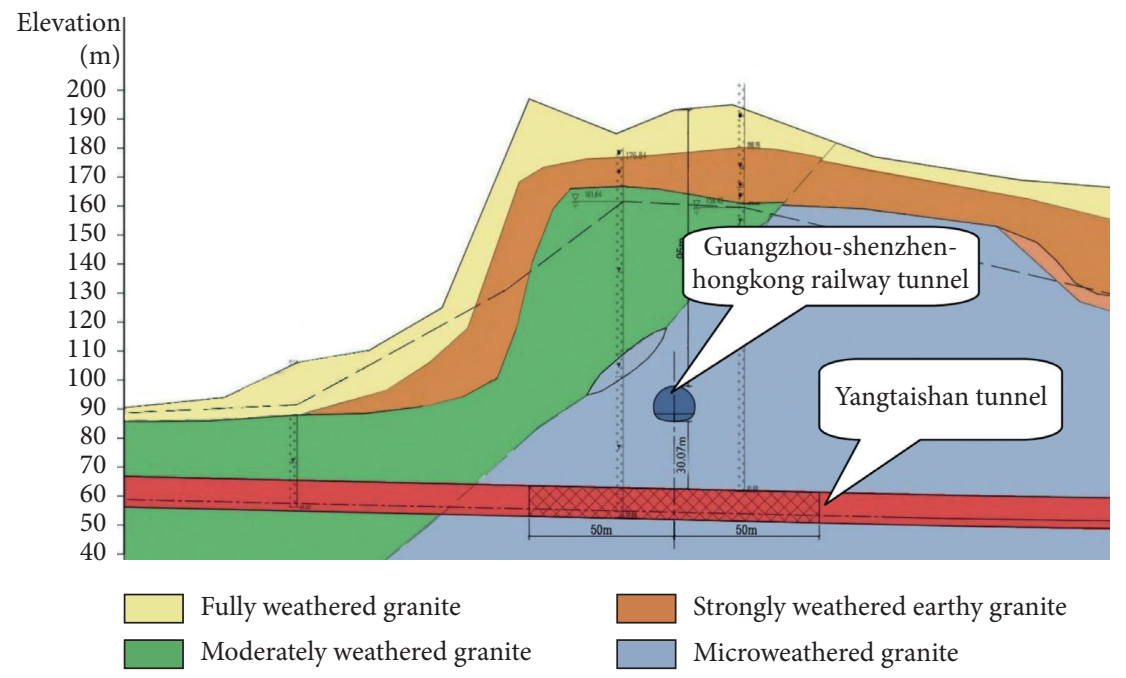

Figure 6: Vertical position of the two tunnels.

TABLE 5: The observed values of evaluation indicators of the railway tunnel.

\begin{tabular}{lccccccccc}
\hline $\begin{array}{l}\text { Evaluation } \\
\text { index }\end{array}$ & $\begin{array}{c}\mathrm{C}_{1} \\
(\mathrm{~m})\end{array}$ & $\begin{array}{c}\mathrm{C}_{2} \\
\left({ }^{\circ}\right)\end{array}$ & $\mathrm{C}_{3}$ & $\begin{array}{c}\mathrm{C}_{4} \\
(\mathrm{~mm})\end{array}$ & $\mathrm{C}_{5}$ & $\mathrm{C}_{6}$ & $\begin{array}{c}\mathrm{C}_{7} \\
(\mathrm{~m})\end{array}$ & $\mathrm{C}_{8}$ & $\mathrm{C}_{9}$ \\
\hline $\begin{array}{l}\text { Observed } \\
\text { value }\end{array}$ & 30.07 & 25 & 50 & 1 & 60 & 5.8 & 125.07 & 80 & 55 \\
\hline
\end{tabular}

3.3. Risk Level Result. Weight vector $W$ and membership matrix $R$ are used to calculate the comprehensive evaluation vector $B$ :

$$
B=W \cdot R=(0.1931,0.4309,0.2940,0.0808,0.0012) .
$$

The risk level corresponding to the maximum membership degree of 0.4309 is level II. Therefore, the risk level of Guangzhou-Shenzhen-Hong Kong Railway Tunnel in tunneling environments of Shenzhen Metro Line 6 is low, which is within the acceptable range according to the relevant regulations [35]; however, attention should be paid to the
TABLE 6: Membership degrees of the eight evaluation indicators.

\begin{tabular}{lccccc}
\hline \multirow{2}{*}{ Evaluation index } & \multicolumn{5}{c}{ Membership degree of evaluation index } \\
& I & II & III & IV & V \\
\hline$C_{1}$ & 0.1300 & 0.5900 & 0.000 & 0.000 & 0.000 \\
$C_{2}$ & 0.000 & 0.0000 & 0.000 & 0.8340 & 0.0117 \\
$C_{3}$ & 0.000 & 0.000 & 1.0000 & 0.000 & 0.000 \\
$C_{4}$ & 0.000 & 0.1354 & 0.3284 & 0.000 & 0.000 \\
$C_{5}$ & 0.000 & 0.0113 & 0.0115 & 0.000 & 0.000 \\
$C_{6}$ & 0.000 & 0.4864 & 0.000 & 0.000 & 0.000 \\
$C_{7}$ & 1.0000 & 0.000 & 0.000 & 0.000 & 0.000 \\
$C_{8}$ & 0.0114 & 0.0112 & 0.000 & 0.000 & 0.000 \\
$C_{9}$ & 0.000 & 0.0113 & 0.0115 & 0.000 & 0.000 \\
\hline
\end{tabular}

deformation monitoring of the Guangzhou-Shenzhen-Hong Kong Railway Tunnel during the construction.

In the actual construction, the maximum settlement and the horizontal displacement of the Guangzhou-ShenzhenHong Kong Railway Tunnel are $0.1 \mathrm{~mm}$ and $0.0213 \mathrm{~mm}$, respectively, which are all less than the control requirements 
TABLE 7: The comparison results of the proposed approach and FAHP.

\begin{tabular}{lcc}
\hline Evaluation method & Evaluation result & Risk level \\
\hline Proposed approach & $(0.1931,0.4309,0.2940,0.0808,0.0012)$ & II \\
FAHP & $(0.2802,0.3627,0.1346,0.1895,0.0330)$ & II \\
\hline
\end{tabular}

of $5 \mathrm{~mm}$ [36]. This is consistent with the result of low-risk level obtained by the model.

\section{Discussion}

In order to further verify the feasibility of the proposed risk assessment approach in this research, Fuzzy Analytic Hierarchy Process (FAHP), a representative of the traditional comprehensive evaluation method, was chosen to work out evaluation results based on the previous case. For space limitation, the detailed computation procedures for FAHP can be referred from Zhu [3]. The obtained risk assessment results based on these two methods are shown in Table 7.

As seen in Table 7, the evaluation results calculated by the cloud model-based approach were fairly consistent with FAHP, indicating that the proposed approach was considerably reliable and efficient. In addition, the membership degree fluctuation range of risk level calculated by the proposed approach is small, indicating that the randomness of the evaluation result of the proposed approach is less likely to lead to deviation, which is more reasonable than the FAHP.

From the perspective of risk level, the safety risk of the Guangzhou-Shenzhen-Hong Kong Railway Tunnel in tunneling construction of Shenzhen Metro Line 6 is low because of the long distance between the two tunnels and $C_{1}$ belongs to risk level I. However, the risk level of the existing tunnel is not only determined by the major evaluation index, such as $C_{1}$, but also determined by other minor evaluation indexes. The risk level of $C_{1}$ is $I$, whereas the evaluation result of the Guangzhou-Shenzhen-Hong Kong Railway Tunnel is level II, indicating that coupling of other influencing factors will lead to increased risks. Therefore, we cannot judge whether the project has risk according to a certain evaluation index. Risk assessment of existing tunnels affected by tunnel construction should be carried out by a professional assessment approach to provide support for the construction plan and emergency plan.

\section{Results}

In recent decades, risk evaluation of existing tunnels adjacent to tunneling construction has attracted broad attention due to the rapid development of underground engineering.[36]:

(1) A risk evaluation index system of existing tunnels adjacent to tunneling construction is proposed according to the tunnel-induced failure mechanism analysis. A cloud model-based risk assessment approach for membership degree was developed. The risk assessment result was obtained by combining risk assessment index weight with a membership degree of risk assessment index. The proposed approach was applied to the safety evaluation of the Guangzhou-Shenzhen-Hong Kong Railway Tunnel in tunneling environments of Shenzhen Metro Line 6. The result has proved to be consistent with the actual situation.

(2) In the conventional fuzzy mathematics method, the sectional fuzzy function should be determined individually concerning each evaluation index. This process was laborious and susceptible to human error, which would affect the accuracy and reliability of the calculated results. Compared with traditional evaluation methods, the proposed cloud modelbased approach was verified to be more competitive solution uncertainty. This approach can directly use the original data without a normalization procedure, avoiding potential information loss. This approach can be used as a decision tool for risk assessment of other similar projects to increase the likelihood of a successful project in an uncertain environment.

\section{Data Availability}

The data used to support the findings of this study are included within the article.

\section{Conflicts of Interest}

The authors declare that they have no conflicts of interest.

\section{Acknowledgments}

This work was supported by the Shaanxi Province Innovation Capability Support Plan-Innovation Team (2020TD005) and Shaanxi Province Housing and Urban-Rural Construction Technology Plan Project (No. 2019-K39).

\section{References}

[1] Z. P. Song, J. C. Mao, X. X. Tian et al., "Optimization analysis of controlled blasting for passing through houses at close range in super large section tunnels," Shock and Vibration, vol. 2019, Article ID 1941436, 16 pages, 2019.

[2] L. M. Zhang, X. G. Wu, Q. Q. Chen et al., "Developing a cloud model based risk assessment methodology for tunnel-induced damage to existing pipelines," Stochastic Environmental Research and Risk Assessment, vol. 29, pp. 523-526, 2014.

[3] K. Zhu, "Fuzzy analytic hierarchy process: fallacy of the popular methods," European Journal of Operational Research, vol. 236, no. 1, pp. 209-217, 2014.

[4] P. S. Kulkarni, S. N. Londhe, and M. C. Deo, "Artificial neural networks for construction management: a review," Journal of Soft Computing in Civil Engineering, pp. 70-88, 2017. 
[5] R. L. Sousa, "Risk analysis for tunneling projects," Doctoral Dissertation, Massachusetts Institute of Technology, Boston, USA, 2010.

[6] W. Yang, X. Xia, B. Pan, C. Gu, and J. Yue, "The fuzzy comprehensive evaluation of water and sand inrush risk during underground mining," Journal of Intelligent and Fuzzy Systems, vol. 30, no. 4, pp. 2289-2295, 2016.

[7] R. Horcik, "Solution of a system of linear equations with fuzzy numbers," Fuzzy Sets Systems, vol. 159, no. 14, pp. 1788-1810, 2008.

[8] S. Q. Lan and Q. H. Zhang, "Risk assessment of deep excavation during construction based on fuzzy theory," Chinese Journal of Geotechnical Engineering, vol. 31, no. 4, pp. 648652, 2009.

[9] H. Zhou and P. Cao, "A fuzzy AHP approach to select supporting schemes for city foundation pit in soft soil," Journal of Central South University (Science and Technology), vol. 43, no. 9, pp. 3582-3588, 2012.

[10] J. J. Chen and Y. J. Zhan, "Quantitative risk assessment model of tunnel construction under passing existing bridges," Journal of Central South University (Science and Technology), vol. 46, no. 5, pp. 1862-1868, 2015.

[11] L. A. Zadeh, "The concept of a linguistic variable and its application to approximate reasoning-I," Information Sciences, vol. 8, no. 3, pp. 199-249, 1975.

[12] D. Y. Li, H. J. Meng, and X. M. Shi, "Membership cloud and membership cloud generators," Computer $R$ and $D$, vol. 32, no. 6, pp. 15-20, 1995.

[13] D. Y. Li and C. Y. Liu, "Study on the universality of the normal cloud model," Engineering Science, vol. 6, no. 8, pp. 28-34, 2004.

[14] D. R. Li, S. L. Wang, and D. Y. Li, Spatial Data Mining Theories and Applications, pp. 150-153, Science Press, Beijing, China, 2006.

[15] W. T. Kong, "Study on the impacts of existing buildings by urban tunnel construction and its safety controlling," Wuhan University, Wuhan, China, 2013, pp. 123-130, Master Degree Thesis.

[16] Z. P. Song, X. X. Tian, Q. Liu et al., "Numerical analysis and application of the construction method for small interval tunnel in the turn line of metro," Science Progress, vol. 103, no. 3, pp. 1-25, 2020.

[17] D. P. Qin, "Analysis of the influence of deformation in metro construction on the safety of adjacent buildings," Doctoral Dissertation, Beijing Jiaotong University, Beijing, China, 2016.

[18] Z. P. Song, Y. Cheng, X. X. Tian et al., "Mechanical properties of limestone from Maixi tunnel under hydro-mechanical coupling," Arabian Journal of Geosciences, vol. 2020, no. 13, pp. $402-414,2020$.

[19] L. Li, M. X. Zhang, H. M. Wu et al., "Influence of shortdistance multi-line overlapped shield tunnelling on deformation of existing tunnels," Chinese Journal of Geotechnical Engineering, vol. 36, no. 6, pp. 1036-1043, 2014.

[20] K. Y. Gao, The Assessment of the Influence of Adjacent Construction on the Safety of Existing Subway Tunnel, Zhejiang University, " Hangzhou, China, 2018.

[21] Z. H. Xiong, "Analysis of the settlement of utility tunnel due to shield tunneling of metro twin tunnels crossing the existing utility tunnel from its bottom," Master Degree Thesis, Southwest Jiaotong University, Chengdu, China, 2015.

[22] Ministry of Railways of the People's republic of China, "Standard for the assessment of the deterioration of railway bridges and tunnels - tunnels," China Railway Publishing House, Beijing, China, 2008.

[23] W. Wang, H. Yuan, Y. Chen, P. Yang, L. Ni, and Y. Li, "A rough set approach to online customer's review mining," Advances in Intelligent and Soft Computing, pp. 229-234, 2012.

[24] D. M. Zhang, X. Zong, and H. W. Huang, "Longitudinal deformation of existing tunnel due to underlying shield tunneling," Rock and Soil Mechanics, vol. 35, no. 9, pp. 2659-2666, 2014.

[25] Q. F. Zhang, T. D. Xia, Z. Ding et al., "Effect of nearby undercrossing tunneling on the deformation of existing metro tunnel and construction control," Rock and Soil Mechanics, vol. 37, no. 12, pp. 3561-3568, 2016.

[26] C. J. Lin, M. Zhang, Z. Q. Zhou et al., "A new quantitative method for risk assessment of water inrush based on variable weight function and improved cloud model," Tunnelling and Underground Space Technology, vol. 95, Article ID 103136, 2020.

[27] D. Li, C. Liu, and W. Gan, "A new cognitive model: cloud model," International Journal of Intelligent Systems, vol. 24, no. 3, pp. 357-375, 2009.

[28] Y. Liu and D. Y. Li, "Statistics on atomized feature of normal cloud model," Journal of Beijing University of Aeronautics and Astronautics, vol. 36, no. 11, pp. 1320-1324, 2010, in Chinese.

[29] S. H. Zhang, M. S. Xiang, X. Zan et al., "Evaluation of water cycle health status based on a cloud model," Journal of Cleaner Production, vol. 245, 2020.

[30] G. Wang, C. Xu, and D. Li, "Generic normal cloud model," Information Sciences, vol. 280, pp. 1-15, 2014.

[31] M. W. Wang, Q. K. Zhu, K. Y. Zhao et al., "A novel cloud model coupled with connection number based on finite intervals for evaluation of surrounding rock stability," Rock and Soil Mechanics, vol. 37, no. 1, pp. 140-165, 2016.

[32] T. L. Saaty, The Analysis Hierarchy Process, McGraw-Hill, NY, USA, 1980.

[33] Y. Wang, "Study on accidents statistical analysis and risk assessment methods of urban subway tunnel," Doctoral Dissertation, Beijing Jiaotong University, Beijing, China, 2018.

[34] T. L. Saaty, "There is no mathematical validity for using fuzzy number crunching in the analytic hierarchy process," Journal of Systems Science and Systems Engineering, vol. 15, no. 4, pp. 457-464, 2006.

[35] Ministry of Railways of the People's republic of China, Temporary Regulation of Railway Tunnel Risk Assessment and Management, China Railway Publishing House, Beijing, China, 2008.

[36] China Railway No.2 Engineering Group Co. LTD, Technical Specification for Monitoring Measurement of Railway Tunnel, China State Railway Group Co., Ltd, Beijing, China, 2015. 